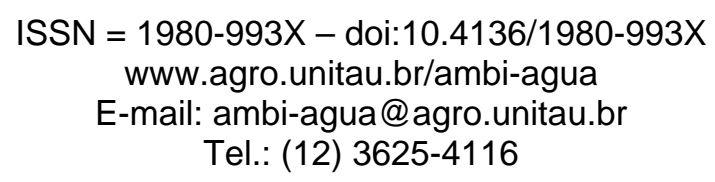

\title{
Aspectos institucionais e outorga de águas subterrâneas para uso industrial no baixo curso do Rio Paraíba, estado da Paraíba, Brasil
}

(doi:10.4136/ambi-agua.93)

\author{
Patrícia Borba Vilar Guimarães ${ }^{1}$; Márcia Maria Rios Ribeiro² \\ ${ }^{1}$ Universidade Federal do Rio Grande do Norte \\ E-mail: patriciaborba@ig.com.br \\ ${ }^{2}$ Universidade Federal de Campina Grande \\ E-mail: mm-ribeiro@uol.com.br
}

\section{RESUMO}

Esse trabalho apresenta um diagnóstico acerca da regulação de outorgas de água subterrânea para o setor industrial no baixo curso do rio Paraíba, PB, com especial atenção no estabelecimento de interações entre o status quo atual e a Política Nacional de Recursos Hídricos (PNRH) que tem por base a Lei Federal no 9.433/97. Complementam-no alguns regulamentos específicos emanados dos órgãos ambientais e da legislação estadual sobre as águas. Com base em dados obtidos em fontes primárias constantes de cadastros de informações fornecidas pelo órgão gestor, análises circunstanciadas do uso de água subterrânea na Região do Baixo curso do Rio Paraíba, com vistas a estabelecer alguns parâmetros que facilitem a implementação da PNRH de forma integrada foram analisadas. A análise dos dados selecionados para o setor industrial mostrou que os volumes outorgados para águas subterrâneas são significativos e diferem bastante entre si. Restou evidenciada a necessidade de incremento constante nos processos de gestão.

Palavras-chave: Gestão de recursos hídricos; Águas subterrâneas; Regulação ambiental.

\section{Institutional aspects and groundwater allocation for industrial uses in low Paraíba river basin, Paraíba state, Brazil}

\begin{abstract}
This paper presents an institutional study of groundwater regulation and industrial use in Paraiba, Brazil, with special emphasis on the interactions between the status quo and the current National Water Resources Policy which is based on Federal Law N ${ }^{0}$ 9.433/97 and some specific regulations in water rights concession issued by the environmental agencies and water legislation. Based on data from primary sources and information provided by water resources management institutes, detailed analyses of groundwater use in order to establish some parameters to facilitate implementation of national policies in an integrated manner were done. The data analysis and the results showed that water resources management processes need to be fostered for the region.
\end{abstract}

Keywords: Water resources management; groundwater; environmental regulation.

\section{INTRODUÇÃO}

As águas subterrâneas são de uma importância ímpar, em razão da sua significativa parcela de contribuição para a formação do ciclo hidrológico. Representam 97\% dos recursos 
hídricos disponíveis ao homem e servem a mais da metade da população mundial, especialmente nas regiões semiáridas (Mierzwa e Hespanhol, 2005). Embora sejam conhecidos os potenciais econômicos, políticos, sociais e ambientais das águas subterrâneas, pouco ainda foi feito em termos de regulação econômica e normas que disciplinem esse importante recurso natural, o que vem se tornando uma forma de perpetuação da utilização desordenada, o que ameaça consideravelmente a sustentabilidade hídrica dos mananciais.

O setor industrial, apesar de, no Brasil, ser apontado como o terceiro usuário de água subterrânea em quantidade, atrás dos usuários domésticos e irrigantes, pelo potencial de impacto que causa nos sistemas ambientais carece de melhor estudo (ANA, 2007a) tanto pelas grandes quantidades de água explotadas, como pelo potencial nocivo dos resíduos que são eventualmente gerados e que têm como destino final os aquíferos.

Esse trabalho tomou por base uma série de dados fornecidos pela Agência Executiva de Gestão das Águas do Estado da Paraíba (AESA) acerca das concessões de outorga de água subterrânea nos últimos 10 anos no estado da Paraíba, entre novembro de 1998 até meados de maio de 2008, analisados sob o enfoque do setor usuário industrial (AESA, 2008). Objetivouse a realização de construção analítica acerca da efetivação da Política Nacional de Recursos Hídricos, no tocante aos instrumentos de gestão, para o usuário selecionado na região estudada.

\section{MATERIAL E MÉTODOS}

Esse trabalho tomou por base uma série de dados fornecidos pela Agência Executiva de Gestão das Águas do Estado da Paraíba (AESA) acerca das concessões de outorga de água subterrânea nos últimos 10 anos no estado da Paraíba, entre novembro de 1998 até meados de maio de 2008, analisados sob o enfoque do setor usuário industrial (AESA, 2008).

Para tratamento analítico dos dados, a revisão de literatura foi centrada na legislação específica para os instrumentos da PNRH e nos elementos de caracterização do estudo de campo.

A maioria dos estados da federação já legislou sobre a gestão dos recursos hídricos. A gestão administrativa local desse recurso natural, por sua vez, nos termos da Lei no 9.433/97 encontra-se delegada aos Comitês de Bacia Hidrográfica criados para permitir a gestão descentralizada do processo decisório, com a participação dos usuários do sistema, do poder público e da sociedade civil (Guimarães e Ribeiro, 2007). Especificamente no tocante às águas subterrâneas, segundo a Constituição Federal, são de domínio estadual (art.26, I) e do Distrito Federal, enquanto aos Municípios não foi atribuída nenhuma espécie de dominialidade sobre as águas (Brasil, 1988). O Município também está integrado na estrutura de gestão dos recursos hídricos (art. 33, IV) pela Lei ${ }^{\circ}$ 9.433/97, embora seja demandada uma evolução na sua atuação, por força da pouca institucionalização no tocante aos entes municipais integrantes do Sistema Nacional de Gestão presentes no Estado Brasileiro.

O tratamento de dominialidade das águas foi elastecido pela Constituição de 1988 para os Estados da Federação, uma vez que "Foi assim consideravelmente ampliado o domínio hídrico daqueles, que passaram a ter incluídos entre seus bens as águas subterrâneas, antes sem titular definido" (Pompeu, 2002, p.50).

Os principais documentos infraconstitucionais disciplinadores da temática das águas subterrâneas no país são resoluções específicas do Conselho Nacional de Recursos Hídricos (CNRH). A Resolução $\mathrm{n}^{\circ}$ 15, de 11 de janeiro de 2001, trata do estabelecimento dos principais conceitos acerca desse tema e a Resolução $\mathrm{n}^{\circ}$ 22, de 24 de maio de 2002, sobre os conteúdos e disciplinamentos dos Planos de Recursos Hídricos relativos às águas subterrâneas. 
São assim definidas por lei as águas subterrâneas, os aquíferos, os corpos hídricos subterrâneos (CNRH, 2001):

Art. $1^{\circ}$ Para efeito desta Resolução consideram-se:

I - Águas Subterrâneas - as águas que ocorrem naturalmente ou artificialmente no subsolo;

II - Águas Meteóricas - as águas encontradas na atmosfera em quaisquer de seus estados físicos;

III- Aquífero - corpo hidrogeológico com capacidade de acumular e transmitir água através dos seus poros, fissuras ou espaços resultantes da dissolução e carreamento de materiais rochosos;

IV - Corpo Hídrico Subterrâneo - volume de água armazenado no subsolo (CNRH, 2001).

Já a Resolução no 22/2002, aponta para a necessidade de integração no planejamento e gestão dos recursos hídricos, pois afirma no seu artigo $5^{\circ}$ que "As ações potencialmente impactantes nas águas subterrâneas, bem como as ações de proteção e mitigação a serem empreendidas, devem ser diagnosticadas e previstas nos Planos de Recursos Hídricos, incluindo-se medidas emergenciais a serem adotadas em casos de contaminação e poluição acidental.” Por força do Parágrafo Único do mesmo artigo, devem os diagnósticos para este fim, envolverem necessariamente a "descrição e previsão da estimativa de pressões socioeconômicas e ambientais sobre as disponibilidades, as estimativa das fontes pontuais e difusas de poluição, a avaliação das características e usos do solo; e a análise de outros impactos da atividade humana relacionadas às águas subterrâneas.” O que amplia a necessidade de estudos interdisciplinares que favoreçam a compreensão desse elemento natural (CNRH, 2002).

A Resolução nº 15/2001 trata a temática dos aquíferos subjacentes no sentido de que:

Art. $4^{\circ}$ No caso de aquíferos subjacentes a duas ou mais bacias hidrográficas, o SINGREH e os Sistemas de Gerenciamento de Recursos Hídricos dos Estados ou do Distrito Federal deverão promover a uniformização de diretrizes e critérios para coleta dos dados e elaboração dos estudos hidrogeológicos necessários à identificação e caracterização da bacia hidrogeológica.

Parágrafo único. Os Comitês de Bacia Hidrográfica envolvidos deverão buscar o intercâmbio e a sistematização dos dados gerados para a perfeita caracterização da bacia hidrogeológica (CNRH, 2001).

Ainda para o caso dos aquíferos transfronteiriços, a mesma Resolução prevê (Art. $5^{\circ}$ ) que "no caso dos aquíferos transfronteiriços ou subjacentes a duas ou mais Unidades da Federação, o SINGREH promoverá a integração dos diversos órgãos dos governos federal, estaduais e do Distrito Federal, que têm competências no gerenciamento de águas subterrâneas”. Para fronteiras entre países, “§ $2^{\circ}$ Nos aquíferos transfronteiriços a aplicação dos instrumentos da Política Nacional de Recursos Hídricos dar-se-á em conformidade com as disposições constantes nos acordos celebrados entre a União e os países vizinhos” (CNRH, 2001). 
Há uma disposição específica nessa Resolução (Art. $6^{\circ}$ ) no sentido de que os Municípios devam ser "orientados" pelos Estados e o Distrito Federal "no que diz respeito às diretrizes para promoção da gestão integrada das águas subterrâneas em seus territórios, em consonância com os planos de recursos hídricos” e em cujas diretrizes “deverão ser propostos mecanismos de estímulo aos Municípios para a proteção das áreas de recarga dos aquíferos e a adoção de práticas de reuso e de recarga artificial, com vistas ao aumento das disponibilidades hídricas e da qualidade da água.” Cabe ainda ao SINGREH o fomento aos estudos para o desenvolvimento dos usos racionais e práticas de conservação dos recursos hídricos subterrâneos, assim como a proposição de normas para a fiscalização e controle desses recursos ( CNRH, 2001, Art. $7^{\circ}$ ).

\subsection{O enquadramento dos corpos d'água}

O enquadramento dos corpos d'água é o estabelecimento do nível de qualidade (classe) a ser alcançado ou mantido em um segmento de corpo d’água ao longo do tempo (ANA, 2007b). Definido como instrumento da PNRH, o enquadramento busca "assegurar às águas qualidade compatível com os usos mais exigentes a que forem destinadas" e a "diminuir os custos de combate à poluição das águas, mediante ações preventivas permanentes” (Art. 9, lei $\mathrm{n}^{\circ}$ 9.433, 1997). Seu significado enquanto instrumento de gestão de recursos hídricos extrapola o espaço de atuação da PNRH, uma vez que representa elemento significativo da PNMA.

O enquadramento é referência para os demais instrumentos de gestão de recursos hídricos (outorga, cobrança, planos de bacia) e instrumentos de gestão ambiental (licenciamento, monitoramento), sendo, portanto, um importante elo entre o Sistema Nacional de Gerenciamento de Recursos Hídricos e o Sistema Nacional de Meio Ambiente - SISNAMA (ANA, 2007b).

A importância do tema da classificação da água em classes diz respeito diretamente aos usos que se pretende fazer dela. A primeira regulamentação genérica surgida a respeito foi consolidada no Código de águas de 1934. O Estado de São Paulo regulamentou o primeiro sistema de classificação dos corpos d’água do país em 1955, por meio do Decreto Estadual $n^{\circ}$ 24.806. Dentre os primeiros estudos sobre o tema, destacaram-se aqueles realizados para o enquadramento dos corpos d'água das bacias do rio Paranapanema, em 1980, e do rio Paraíba do Sul, em 1981, conforme as classes estabelecidas pela Portaria $n^{0}$ 13/76 do Ministério do Interior. Esse documento originou as legislações sobre o enquadramento dos estados de São Paulo (1977), Alagoas (1978), Santa Catarina (1979), Rio Grande do Norte (1984). Ao longo dos anos 1980 e 1990, alguns estados realizaram os enquadramentos de seus corpos d'água principais ou de algumas bacias selecionadas: Paraíba (1988), Paraná (entre 1989 e 1991), Rio Grande do Sul (entre 1994 e 1998), Minas Gerais (entre 1994 e 1998), Bahia (1995 e 1998) e Mato Grosso do Sul (1997) (ANA, 2007b). A década de 80 foi decisiva para a consolidação da regulamentação do enquadramento, culminando com a Resolução n 20/86 do CONAMA, que por muito tempo serviu de norteamento da questão do enquadramento. No ano de 2000, a Resolução CNRH $\mathrm{n}^{\circ} 12$ estabeleceu os procedimentos para o enquadramento dos cursos d'água em classes de qualidade, definindo as competências para elaboração e aprovação da proposta de enquadramento e as etapas a serem observadas (CNRH, 2000). Em 2005, a Resolução CONAMA no 357 (CONAMA, 2008) substituiu a Resolução CONAMA n 20/86. Essa Resolução define a classificação das águas doces, salobras e salinas em função dos usos 
preponderantes (sistema de classes de qualidade) atuais e futuros, embora ainda sem consideração específica acerca das águas subterrâneas.

Segundo dados da ANA (2007a), das 27 unidades da federação, 17 tratam do enquadramento como um instrumento da Política Estadual de Recursos Hídricos. Hídricos. Em 14 unidades da federação, fica explícito que o enquadramento fará parte do Plano de Recursos Hídricos. É importante ressaltar que, institucionalmente, cabe às Agências de Bacia, em 16 unidades da federação, a elaboração da proposta de enquadramento, mesmo considerando que, na grande maioria dos estados e bacias, as agências ainda não foram implantadas. Nos estados do Acre, Amapá, Pará, Espírito Santo e no Distrito Federal há possibilidade do órgão gestor de recursos hídricos elaborar sua proposta de enquadramento (ANA, 2007b).

Especificamente no tocante ao enquadramento de águas subterrâneas, há regulamentação específica contida na Resolução $n^{\circ}$ 396/08. O artigo $2^{\circ}$ fornece todas as definições necessárias à interpretação desta, passando a classificar as águas subterrâneas em 5 classes, no artigo $3^{\circ}$ (CONAMA, 2008).

A Resolução $n^{\circ}$ 396/2008 do CONAMA vem reforçar formalmente a integração desejada entre a Política Nacional do Meio Ambiente (PNMA) e a PNRH, "a fim de garantir as funções social, econômica e ambiental das águas subterrâneas”, quando determina que "Art. $1^{\circ}$ - Esta Resolução dispõe sobre a classificação e diretrizes ambientais para o enquadramento, prevenção e controle da poluição das águas subterrâneas” (CONAMA, 2008). Trata-se, portanto, de mecanismo regulatório específico de apoio à gestão de águas subterrâneas.

O sentido dessa norma procura conjugar aspectos físicos relacionados às águas subterrâneas, como o fato de que "os aquíferos se apresentam em diferentes contextos hidrogeológicos e podem ultrapassar os limites de bacias hidrográficas”, bem como o fato de que "as águas subterrâneas possuem características físicas, químicas e biológicas intrínsecas, com variações hidrogeoquímicas, sendo necessário que as suas classes de qualidade sejam pautadas nessas especificidades”. A classificação objetiva, naturalmente, o estabelecimento de referências acerca dos aspectos intrínsecos que determinam sua qualidade e viabilizar o enquadramento em classes. Outro aspecto relevante é a consideração de que a "prevenção e controle da poluição estão diretamente relacionados aos usos e classes de qualidade de água exigida para um determinado corpo hídrico subterrâneo" e que a promoção e proteção da qualidade das águas subterrâneas é um fato que merece cuidados extremos em razão de que os processos de recuperação são lentos e onerosos (CONAMA, 2008).

A Resolução estabelece, em termos gerais, a necessidade de articulação entre os órgãos gestores de recursos hídricos, saúde e meio-ambiente, pois no artigo 21 menciona a necessidade de restrição de áreas de proteção de aquíferos e poços, a saber:

Art. 20. Os órgãos ambientais em conjunto com os órgãos gestores dos recursos hídricos deverão promover a implementação de Áreas de Proteção de Aquíferos e Perímetros de Proteção de Poços de Abastecimento, objetivando a proteção da qualidade da água subterrânea.

Como aspecto relevante, essa Resolução traduz expressamente a necessidade de gestão compartilhada das águas subterrâneas pelos órgãos tradicionais de gestão, colocados pela PNRH, pelos órgãos ambientais e pelos agentes de saúde, com vistas à prevenção de poluição e contaminação dos aquíferos:

Art. 21. Os órgãos ambientais, em conjunto com os órgãos gestores dos recursos hídricos e da saúde, deverão 
promover a implementação de Áreas de Restrição e Controle do Uso da Água Subterrânea, em caráter excepcional e temporário, quando, em função da condição da qualidade e quantidade da água subterrânea, houver a necessidade de restringir o uso ou a captação da água para proteção dos aquíferos, da saúde humana e dos ecossistemas.

Parágrafo único. Os órgãos de gestão dos recursos hídricos, de meio ambiente e de saúde deverão articular-se para definição das restrições e das medidas de controle do uso da água subterrânea.

Art. 22. As restrições e exigências da classe de enquadramento das águas subterrâneas, aprovado pelo conselho de recursos hídricos competente, deverão ser observadas no licenciamento ambiental, no zoneamento econômico-ecológico e na implementação dos demais instrumentos de gestão ambiental (CONAMA, 2008).

Segue, na Tabela 1, uma síntese dos principais elementos legais disciplinadores dessa temática em nível federal.

Tabela 1. Panorama Nacional das Leis e Resoluções sobre águas superficiais e subterrâneas.

\begin{tabular}{|c|c|}
\hline Leis e Resoluções & Especificação \\
\hline Lei 9.433/97 & $\begin{array}{l}\text { Institui a Política Nacional de Recursos Hídricos e } \\
\text { cria o Conselho Nacional de Recursos Hídricos e o } \\
\text { Sistema Nacional de Gerenciamento de Recursos } \\
\text { Hídricos. }\end{array}$ \\
\hline Resolução CNRH 15/01 & $\begin{array}{l}\text { Estabelece diretrizes gerais para a gestão de águas } \\
\text { subterrâneas. }\end{array}$ \\
\hline Resolução CNRH 22/02 & $\begin{array}{l}\text { Estabelece diretrizes para inserção das águas } \\
\text { subterrâneas no instrumento Planos de Recursos } \\
\text { Hídricos. }\end{array}$ \\
\hline $\begin{array}{l}\text { Resolução CONAMA } \\
\text { 20/86 }\end{array}$ & $\begin{array}{l}\text { Dispõe sobre a classificação das águas doces, } \\
\text { salobras e salinas do Território Nacional. }\end{array}$ \\
\hline $\begin{array}{l}\text { Resolução CONAMA } \\
357 / 05\end{array}$ & $\begin{array}{l}\text { Dispõe sobre a classificação dos corpos de água e } \\
\text { diretrizes ambientais para o seu enquadramento, bem } \\
\text { como estabelece as condições e padrões de } \\
\text { lançamento de efluentes, e dá outras providências. }\end{array}$ \\
\hline $\begin{array}{l}\text { Resolução CONAMA } \\
396 / 08\end{array}$ & $\begin{array}{l}\text { Dispõe sobre a classificação e diretrizes ambientais } \\
\text { para o enquadramento das águas subterrâneas e dá } \\
\text { outras providências. }\end{array}$ \\
\hline
\end{tabular}

\subsection{A Outorga das águas subterrâneas}

Existe ainda uma relação direta entre o enquadramento dos corpos de água com o instrumento de outorga, em razão de dispositivos da Lei $n^{\circ} 9.433 / 97$, uma vez que a outorga (Art. 13) “(...) deverá respeitar a classe em que o corpo de água estiver enquadrado (...)”. Em função desse dispositivo, todas as análises de pedidos de outorga, seja de captação de água ou de lançamento de efluentes, deverão considerar as condições de qualidade estabelecidas pelas classes de enquadramento. Institucionalmente, cabe ao Comitê de Bacia Hidrográfica (CBH) 
a responsabilidade pela aprovação da proposta de enquadramento dos corpos de água em classes de uso, para posterior encaminhamento ao respectivo Conselho de Recursos Hídricos Nacional ou Estadual, de acordo com o respectivo domínio dos corpos de água. Sob o aspecto institucional, por força da Resolução $n^{0} 12 / 02$ do CNRH, cabe às agências de águas proporem aos $\mathrm{CBH}$ os critérios técnicos para o enquadramento. Diante das condições de implantação desse ente no SINGREH, a ANA já recomenda a revisão dessa Resolução, com vistas à ampliação da competência técnica para a proposta de critérios para o enquadramento (ANA, 2007b).

O processo de definição dos critérios de enquadramento envolve o diagnóstico dos elementos do sistema ambiental em cada bacia hidrográfica, nos seus usos atuais e futuros, numa abordagem que leve em conta as vocações econômicas e condicionantes sócioambientais dos usos não só das águas superficiais, como da água subterrânea. O instrumento da outorga, nos termos da PNRH, é um mecanismo útil para garantir a sustentabilidade e proteção, tanto de águas superficiais quanto dos aquíferos, no tocante à qualidade e quantidade da captação da água subterrânea, de modo que critérios para emissão da outorga de águas deverão ser baseados em estudos sobre a disponibilidade hídrica subterrânea e a vulnerabilidade dos aquíferos à contaminação.

A natureza geopolítica da água requer processos integrativos e participativos de gestão, que contribuam para o controle de desperdícios, mau uso e poluição. Uma peculiaridade importante diz respeito à caracterização das águas minerais, de origem subterrânea. Segundo o Código de Águas Minerais de 1945, alterado pela Lei nº 6.726/79, as águas subterrâneas podem vir a ser consideradas minerais, se "provenientes de fontes naturais ou artificialmente captadas que possuam composição química ou propriedades físicas ou físico-químicas distintas das águas comuns, com características que lhes confiram ação medicamentosa"1 (Brasil, 1945).

Segundo dados da ANA (2007a), existem hoje 70.660 outorgas de direito de usos dos recursos hídricos em águas de domínio dos Estados e da União, relativas a usos consuntivos, totalizando $2.044 \mathrm{~m}^{3} / \mathrm{s}$. Desse total, $1.955 \mathrm{~m}^{3} / \mathrm{s}$ são correspondentes a 50.112 outorgas de águas superficiais, e $89 \mathrm{~m}^{3} / \mathrm{s}$ correspondem a 20.548 outorgas de águas subterrâneas. Há 1.512 outorgas em rios de domínio da União, com uma vazão total outorgada de $629 \mathrm{~m}^{3} / \mathrm{s}$, e 69.148 outorgas em rios de domínio dos Estados e águas subterrâneas, totalizando $1.415 \mathrm{~m}^{3} / \mathrm{s}$ (Tabela 2).

Tabela 2. Outorgas para captação de água no Brasil.

\begin{tabular}{lccrrr}
\hline Descrição & Superficiais & Subterrâneas & União & Estados & Total \\
\hline Número de outorgas & 50.112 & 20.543 & 1.512 & 69.148 & 70.660 \\
Vazão outorgada $\left(\mathrm{m}^{3}\right)$ & 1.955 & 89 & 629 & 1.415 & 2.044 \\
\hline
\end{tabular}

Fonte: (ANA, 2007a).

\subsection{A regulação das águas subterrâneas no Estado da Paraíba}

O Sistema Aquífero Paraíba-Pernambuco é o sistema de maior e melhor potencial hídrico do Estado da Paraíba e ocupa uma área de cerca de $3.400 \mathrm{~km}^{2}$ na região litorânea, situada ao leste do Estado. Tem por arcabouço as formações que compõem a bacia sedimentar de mesmo nome. Os recursos hídricos desse sistema no Estado da Paraíba se repartem entre as bacias hidrográficas que drenam a região litorânea dos rios Abiaí, Gramame, Paraíba (Baixo Curso), Miriri, Mamanguape (Baixo Curso), Camaratuba (Médio e Baixo cursos) e Guaju (SEMARH, 2006). Esse sistema contempla a bacia hidrográfica do maior rio perene do Estado, o Rio

\footnotetext{
${ }^{1}$ A delimitação empregada neste trabalho pretende analisar aspectos das águas subterrâneas não enquadradas em regulamentações específicas sobre águas minerais.
} 
Paraíba, na sua porção baixa. Em razão da intensa movimentação econômica da região, favorecida pelo uso intensivo de fontes de água subterrânea para além da subsistência, este estudo está delimitado nessa porção. A Bacia Hidrográfica do Rio Paraíba localiza-se na Região Hidrográfica Atlântico Nordeste Oriental (ANA, 2007a). A Figura 1 apresenta o mapa das bacias hidrográficas da Paraíba, com destaque para Região do Baixo Curso do Rio Paraíba.

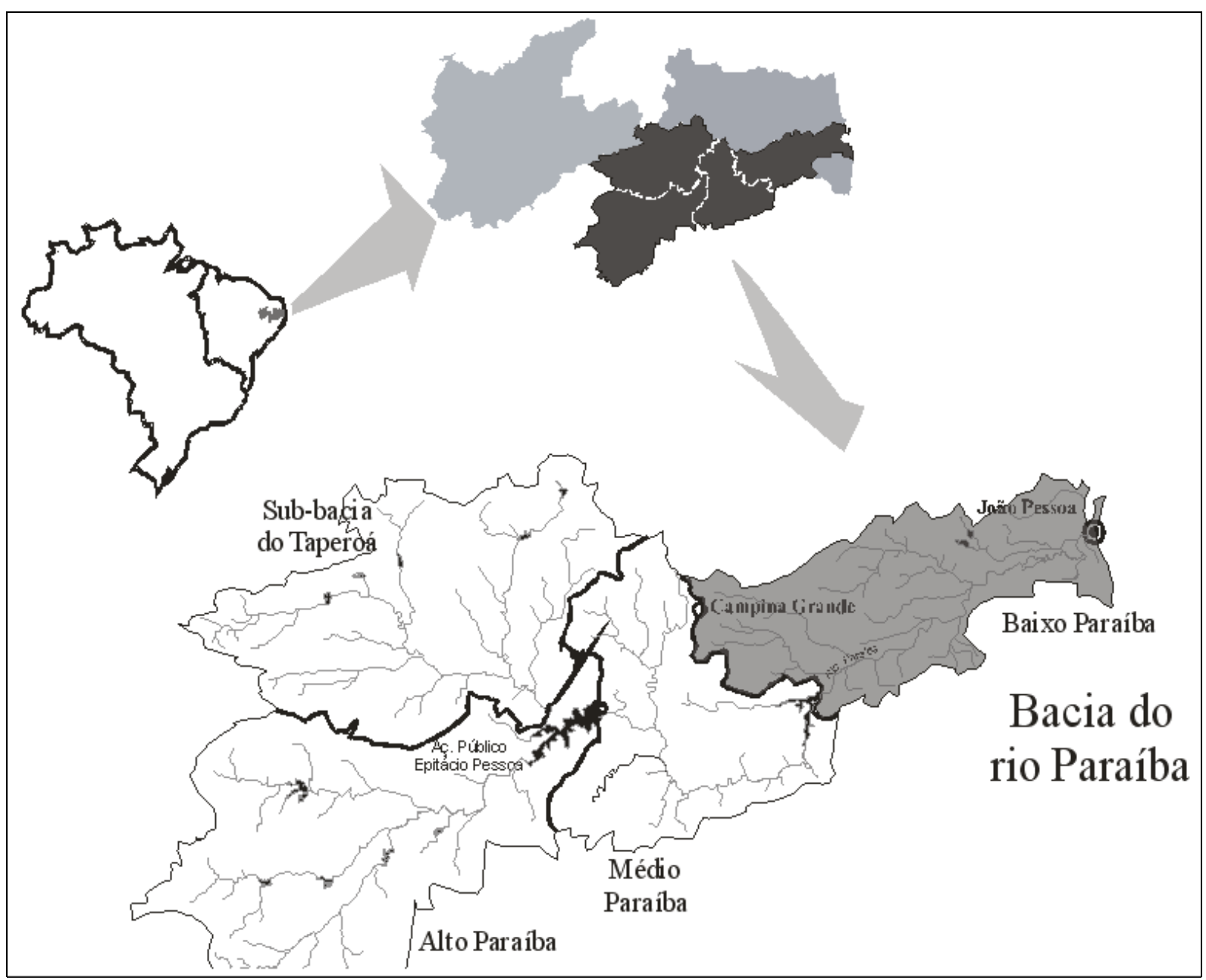

Figura 1. Localização da região do Baixo Curso do rio Paraíba.

A Resolução $n^{0} 1$ do CERH-PB divide a Bacia Hidrográfica do Rio Paraíba em quatro regiões: sub-bacia do rio Taperoá, Região do Alto Curso do Rio Paraíba, Região do Médio Curso do Rio Paraíba e Região do Baixo Curso do Rio Paraíba. A porção do Baixo Paraíba destaca-se por abrigar cidades importantes sob o aspecto de representarem densos aglomerados urbanos e intensa atividade econômica. O uso de água nessa região apresenta-se bastante intensificado, por força de diversas atividades demandantes intensas de água, como a produção industrial e a irrigação. A Região do Baixo Curso do Rio Paraíba está na área de abrangência do CBH-Paraíba ${ }^{2}$.

O órgão gestor dos recursos hídricos paraibanos é a Agência Executiva de Gestão das Águas do Estado da Paraíba (AESA) criada pela Lei n 7.779 , de 07/07/2005, sob a forma jurídica de uma autarquia, vinculada à Secretaria de Estado de Ciência e Tecnologia e do Meio Ambiente (SECTMA). O Plano Estadual de Recursos Hídricos do Estado da Paraíba

\footnotetext{
2“Art. $2^{0}$ O CBH-PB abrangerá 85 (oitenta e cinco) Municípios, distribuídos na Sub-Bacia Hidrográfica do Rio Taperoá e nas Regiões Hidrográficas do Baixo, Médio e do Alto Curso do Rio Paraíba (...)” (CBH-PB, 2007).
} 
(PERH-PB) constitui-se no documento mais atual de referência para a gestão no estado, complementado pelas resoluções editadas pelo CERH e pelos CBH em atividade.

Mediante a Lei estadual $n^{0}$ 6.308/1996, alterada pela Lei $n^{0} 8.446 / 2007$, o estado da Paraíba legislou sobre a política de gestão de águas no estado, no sentido de estabelecer a integração dos instrumentos de gestão de águas superficiais e subterrâneas. O estado regulamentou a outorga do direito de uso de águas mediante os decretos de 31 de outubro de 1997 e n ${ }^{0}$ 25.563/2004, que estabelece compensações procedimentais na concessão de outorga (Paraíba, 1997, 2004).

Os princípios da gestão estão condicionados, em linhas gerais, à integração de entes e elementos do ciclo hidrológico:

\begin{abstract}
Art. $4^{\circ}$ A concessão, fiscalização e controle da outorga serão estabelecidos por princípios programáticos estabelecidos pela Secretaria Extraordinária do Meio Ambiente, dos Recursos Hídricos e Minerais, com a necessidade de: (...)

III - planejar e gerenciar, de forma integrada, descentralizada e participativa, o uso múltiplo, o controle, a conservação, a proteção e a preservação dos recursos hídricos, cuidando para que não haja dissociação dos aspectos qualitativos e quantitativos, considerando as fases aérea, superficial e subterrânea do ciclo hidrológico; (Paraíba, 1997).
\end{abstract}

A regulamentação de outorga no estado preza, portanto, pela integração entre elementos de gestão de águas superficiais e subterrâneas, como especialmente evidenciado no artigo $5^{\circ}$ do Decreto de outorga (Paraíba, 1997).

A análise por setor usuário apresenta-se especialmente significativa no contexto dos estados, pois, ao exemplo da Paraíba, deverá haver previsão ao menos genérica de compatibilização dos usos com o desenvolvimento sustentável no tocante às atividades econômicas e a proteção social (art. 3º). (Paraíba, 1997).

\title{
3. RESULTADOS E DISCUSSÃO SOBRE A OUTORGA NO ESTADO DA PARAÍBA
}

O setor industrial no estado da Paraíba está caracterizado como de médio porte, comparado às demais regiões industrializadas do país. Pesquisa Industrial Anual-empresa do IBGE indica o número de unidades locais no estado em 1.302 (IBGE, 2005). Dos dezoito municípios na área de abrangência do Baixo Rio Paraíba estão os mais industrializados do estado, à exceção de Campina Grande: Santa Rita, Bayeux, Cabedelo e João Pessoa.

Segundo dados do cadastro de outorgas da AESA, o setor industrial, com o uso da água de poço, apresenta-se bastante significativo (Figura 2; Tabela 3). Desde a implantação de outorga na Paraíba, em 1998 até meados de maio de 2008, tramitaram no órgão gestor 64 processos relativos às águas subterrâneas na Região do Baixo Curso do Rio Paraíba com a finalidade industrial. Sendo 54 outorgados (Tabela 3) e 10 em andamento. Ressaltando que das outorgas emitidas, 70,37\% encontram-se vencidas, ou seja, das 54 emitidas, 38 estão com as validades expiradas. Do total do volume outorgado no setor industrial da Bacia do Rio Paraíba, 97,33\% estão no baixo Paraíba e 2,67\%, nas outras regiões hidrográficas (Alto, Médio e Taperoá).

Foi observado que de todas as outorgas concedidas, 99,95\% referem-se às outorgas quantitativas (por retirada da água bruta) e apenas 0,05\%, para lançamento de efluentes. 
Tabela 3. Outorgas de água subterrânea do usuário industrial da Paraíba (Nov./1998 a mai./2008).

\begin{tabular}{ccc}
\hline $\begin{array}{c}\text { Outorgas Superficiais e } \\
\text { subterrâneas no estado da } \\
\text { Paraíba (uso industrial) }\end{array}$ & $\begin{array}{c}\text { Total } \\
\text { outorgado } \\
\text { (m } \mathbf{3} / \mathbf{a n o})\end{array}$ & $\begin{array}{c}\text { Número de } \\
\text { outorgas } \\
\text { concedidas }\end{array}$ \\
\hline 1998 & $4.080,00$ & 01 \\
1999 & $422.712,00$ & 05 \\
2000 & $35.220,00$ & 02 \\
2001 & $534.080,00$ & 05 \\
2002 & $210.340,00$ & 07 \\
2003 & $72.147,00$ & 03 \\
2004 & $585.171,84$ & 08 \\
2005 & $357.060,00$ & 06 \\
2006 & $130.608,00$ & 09 \\
2007 & $131.614,00$ & 07 \\
2008 & $134.320,00$ & 01 \\
\hline Total & $\mathbf{2 . 6 1 2 . 2 7 2 , 8 4}$ & $\mathbf{5 4}$ \\
\hline
\end{tabular}

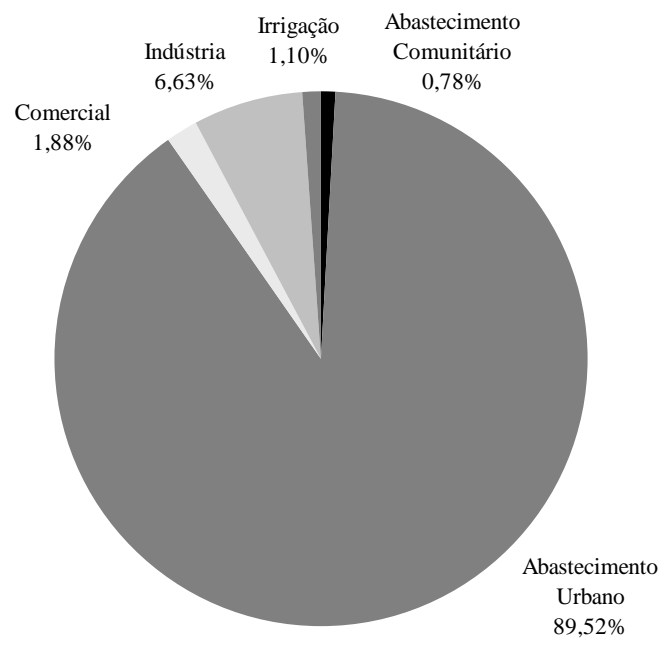

Figura 2. Percentual outorgado para água subterrânea por setor usuário na Região do Baixo Paraíba (agosto de 1998 a maio de 2008).

Para o uso industrial, considerando as águas superficiais e subterrâneas, foram emitidas 60 outorgas no Baixo Curso do Rio Paraíba, sendo 90\% de águas subterrâneas e 10\% de águas superficiais. 


\section{CONCLUSÕES}

A análise dos dados selecionados para o setor industrial no Estado da Paraíba mostrou que os volumes outorgados para águas subterrâneas são significativos e diferem bastante entre si. Verificou-se que do total de outorgas concedidas para águas subterrâneas para o setor industrial na Bacia do Rio Paraíba mais da metade delas (70,37\%) estão vencidas. Isso demonstra a necessidade de incremento constante nos processos de gestão.

A análise demonstrou que se trata de um processo de institucionalização que já possui dez anos, constituindo-se logo após, portanto, da criação da Política Nacional de Recursos Hídricos. Isso não significa dizer, entretanto, que haja plena integração dos sistemas de gestão de águas superficiais e subterrâneas, conforme concebido pelo legislador. Sob o ponto de vista dos instrumentos de regulação e gestão, a cobrança no estado, por exemplo, está em vias de institucionalização e ainda não foi implantada para as águas superficiais.

A legislação brasileira dá os primeiros passos para o tratamento conjunto das águas subterrâneas e superficiais. Entretanto, ocorrem especificidades e detalhamentos que necessitam ser trabalhadas, tanto para os instrumentos de enquadramento como de outorga de água subterrânea em cada estado.

\section{AGRADECIMENTOS}

Esta pesquisa se insere no âmbito do projeto "Integração dos instrumentos de outorga, enquadramento e cobrança para a gestão das águas subterrâneas” financiado pelo MCT/FINEP/CT-HIDRO. Os autores agradecem às instituições mencionadas.

\section{REFERÊNCIAS}

ALBUQUERQUE, José do Patrocínio Tomaz. Estudo hidrogeológico da bacia sedimentar Pernambuco-Paraíba no estado da Paraíba. 2005. (documento não publicado).

AGÊNCIA EXECUTIVA DE GESTÃO DAS ÁGUAS DO ESTADO DA PARAÍBA AESA. Cadastro de Outorgas da Bacia do Rio Paraíba. Disponível em: $<$ http://www.aesa.pb.gov.br>. Acesso em: 17 de dezembro. 2008

AGÊNCIA NACIONAL DE ÁGUAS ANA . Disponibilidades e demandas de recursos hídricos. Cadernos de Recursos Hídricos, Brasília, v. 2, 2007a. Disponível em: $<$ http://www.ana.gov.br/sprtew/recursoshidricos.asp>. Acesso em: 16 de outubro. 2008

AGÊNCIA NACIONAL DE ÁGUAS ANA. Panorama do Enquadramento dos Corpos d'Água do Brasil/Panorama da Qualidade das Águas Subterrâneas no Brasil. Cadernos de Recursos Hídricos, Brasília, v. 5, 2007b. Disponível em <http://www.ana.gov.br/sprtew/5/5-ANA.swf>. Acesso em: 10 de março. 2008.

AGÊNCIA NACIONAL DE ÁGUAS ANA. Diagnóstico da outorga de direito de uso de recursos hídricos no Brasil. Cadernos de Recursos Hídricos, Brasília, v. 4, 2007c. Disponível em: <http://www.ana.gov.br/sprtew/4/4-ANA.swf > . Acesso em: 15 de maio. 2008.

BRASIL. Constituição da República Federativa do Brasil. Brasília: Senado Federal, 1988.

BRASIL. Decreto-lei no 7.841, de 8 de agosto de 1945. Código de águas minerais.

BRASIL. Lei $n^{0}$ 9.433, de 08 de janeiro de 1997. Institui a Política Nacional de Recursos Hídricos, cria o Sistema Nacional de Gerenciamento de Recursos Hídricos. Disponível em: <http://www.planalto.gov.br/CCIVIL/leis/L9433.htm>. Acesso em: 12 de outubro. 2008. 
BRASIL. Ministério do Meio Ambiente. Gestão ambiental no Brasil. Um Compromisso com o Desenvolvimento Sustentável. Brasília: MMA, 2001.

CONSELHO NACIONAL DE RECURSOS HÍDRICOS CNRH. Resolução CNRH n $\mathbf{n}^{\mathbf{1}} \mathbf{1 2}$, de 19/07/2000. Brasília: MMA, 2000.

CONSELHO NACIONAL DE RECURSOS HÍDRICOS CNRH . Resolução CNRH n ${ }^{\mathbf{1}}$ 15, de 11/01/2001. Brasília: MMA, 2001.

CONSELHO NACIONAL DO MEIO AMBIENTE CONAMA. Resolução CONAMA no 396, de 07/04/2008. Brasília: MMA, 2008.

GUIMARÃES, Patrícia Borba Vilar; RIBEIRO, Márcia Maria Rios. Desafios da cobrança pelo uso da água no contexto federativo nacional de competências. In: SIMPÓSIO BRASILEIRO DE RECURSOS HÍDRICOS, 17., João Pessoa Anais... São Paulo: ABRH, 2007.

INSTITUTO BRASILEIRO DE GEOGRAFIA E ESTATÍSTICA IBGE. Pesquisa Industrial Anual: empresa. Diretoria de Pesquisas, Coordenação de Indústria. Disponível em: <http://www.ibge.gov.br/estadosat/temas.php?sigla=pb\&tema=piaempresa2005>. Acesso em: 23 maio 2008.

BRASIL. Ministério do Meio Ambiente. Secretaria de Recursos Hídricos. MMA/SRH. Avaliação das águas do Brasil. Brasília: MMA, 2002.

MIERZWA, José Carlos; HESPANHOL, Ivanildo. Água na indústria: uso racional e reuso. São Paulo: Oficina de textos, 2005. 143p.

PARAÍBA. Lei $\mathbf{n}^{\circ}$ 6.308, de 02 de julho de 1996. Com as alterações e revogações introduzidas pelas Leis $n^{\circ}$ 6.544/1997 e $n{ }^{\circ}$ 8.446/2007. Institui a Política Estadual de Recursos Hídricos, suas diretrizes e dá outras providências. Disponível em: <http://www.aesa.pb.gov.br/cerh/legisl_cerh-pb/Lei\%20n.\%206.308_96\%20-\%20Politica\%20Estadual\% 20-\%20Atualizada\%20em\%202006.pdf>. Acesso em: 10 de maio. 2008.

Decreto n ${ }^{0}$ 19.260, de 31 de outubro de 1997. Regulamenta a Outorga do Direito de Uso dos Recursos Hídricos. Disponível em: <http://www.aesa.pb.gov.br/legislacao/ decretos/estadual/19260_97_outorga_agua.pdf>. Acesso em: 10 de maio. 2008.

Decreto $\mathbf{n}^{0}$ 25.563, de 09 de dezembro de 2004. Estabelece Critérios e Valores para Compensação dos Custos da Outorga. Estabelece os critérios e valores para compensação dos custos de análise do processo e vistoria para fins de outorga de direito de uso de recursos hídricos. Disponível em: <http://www.aesa.pb.gov.br/legislacao/decretos/ estadual/25_563_04_valores_custos_outorga.pdf>. Acesso em: 15 de abril. 2008.

POMPEU, C. T. Direito de águas no Brasil. São Paulo: RT, 2006. 512p.

SECRETARIA EXTRAORDINÁRIA DO MEIO AMBIENTE, DOS RECURSOS HÍDRICOS E MINERAIS DA PARAIÍBA Plano estadual de recursos hídricos do Estado da Paraíba PERH-PB. João Pessoa: SEMARH, 2006. 